\title{
Assessment of Factors Influencing Practical Work in Chemistry: A Case of Secondary Schools in Wolaita Zone, Ethiopia
}

\author{
Mathewos Anza ${ }^{a^{*}}$, Mesfin Bibiso $^{a}$, Abedelfeta Mohammad ${ }^{a}$, Berhanu Kuma ${ }^{b}$ \\ ${ }^{a}$ College of natural and computational science, Department of Chemistry, Wolaita Sodo University, P. O. Box \\ 138, Wolaita Sodo, Ethiopia. \\ ${ }^{b}$ College of Agriculture, Department of Agricultural Economics, Wolaita Sodo University, P. O. Box 138, \\ Wolaita Sodo, Ethiopia.
}

\begin{abstract}
The purpose of this study is to explore factors that influence practical work in chemistry for secondary schools in Wolaita Zone, Ethiopia. The study has identified teachers', learners' and school principals' perceptions to indicate the key factors that seem to inhibit the effective use of practical work in chemistry. The sample for the study comprised 56 chemistry teachers, 75 secondary school students, and 5 school principals. Data were collected using structured questionnaires, focus group discussion and interview. The collected data were analyzed using simple quantitative and qualitative analysis. The finding of the study revealed that factors that influencing practical work in chemistry of secondary schools are teachers' poor knowledge of practical work, full-time occupancy of chemistry teachers, absenteeism of the teacher at practical classes, late commencement of teaching a practical class; lack of awareness and motivation of school managements and unsafe working environments. Furthermore, lack of separate chemistry laboratory, lack of equipment in the laboratory, too short period allocated for practical work, low attitude students' toward practical work in chemistry, teachers' low level of expectation for the development of Information and communication technology (ICT) were the major factors that affect the practical work in chemistry. Finally, recommendations were forwarded based on the major finding in order to improve practical work in chemistry.
\end{abstract}

Index Terms: Practical work, laboratory, software application.

(C) 2016 Published by MECS Publisher. Selection and/or peer review under responsibility of the Research Association of Modern Education and Computer Science.

\section{Introduction}

Science education has aimed to help students to gain an understanding of as much of the established body of scientific knowledge as is appropriate to their needs, interests and capacities and to develop students'

\footnotetext{
* Corresponding author: Mathewos Anza Tel.: +251913348379; Fax: +251465515113

E-mail address: mathewosanza@gmail.com
} 
understanding of the methods by which this knowledge has been gained and our grounds for confidence in it [1]. Given the potential benefits, the provision of quality science education to all children will have a far reaching consequence on a countries' development prospect. Therefore, based on the aim of science education at all levels practical activities in science education are regarded as one of the necessary elements to promote understanding of scientific principles. The importance of practical work in science is widely accepted and it is acknowledged that good practical work promotes the engagement and interest of students as well as developing a range of skills, science knowledge, and conceptual understanding [2]. While practical work is considered essential in chemistry teaching, it is also associated with a number of burdens including the high cost of equipment and chemicals, chemical hazard risk, and environmental pollution. Furthermore, practical work requires more time and the presence of qualified and experienced teachers and technical assistants.

In the Ethiopian context, chemistry teaching has undergone continuous changes in its objective, contents, teaching-learning methods and curriculum materials. The education and training policy of Ethiopia emphasizes the development of problem-solving capacity in the content of education, curriculum structure and approach, focusing on acquisition of chemical knowledge to be used in solving personal and societal problems. Similarly, it is stated that achieving the vision of transforming Ethiopia into a middle-income country in 2025 demands transformation of the economy through the application of chemical knowledge and technology as an instrument to create wealth [3]. Thus, it is important to emphasize on chemical science and technology so as to produce capable citizens who can contribute to make the country well competitive globally through knowledge. The prevailing problem of practical work implementation in chemistry has a wide range of practical process. These practical processes includes the factors influencing practical activities, the ways that science teachers make practical design; the way the teachers get prepared before carrying out the practical work; the extent of the practical works being carried out based on the guidance of teachers (implementation) and the vitality of the students' achievements and performance for teachers etc.

The present study is aimed at assessing the factors that influencing practical work in the chemistry of secondary schools in Wolaita zone, Southern Ethiopia. It is very important to assess and investigate the major constraints that secondary schools are encountering in the implementation of practical activities and how schools tackle the imbalance between theoretical and practical aspects in teaching chemistry. The results of the study will provide insight for policy makers and developers the way how to monitor the regular implementation of practical activities in schools as planned by the curriculum and feedbacks for schools to develop their capacities by fulfilling basic facilities of laboratory and by solving the problems associated with them; help the identify the need for implementation of periodical workshops, seminars and training for science teachers of schools on science practical work so that they update their skill and experience and encourage other science educators to conduct further research on the same topic. This study is aimed at answering the following research questions:

- What are the teachers', learners' and schools' leaders' perceptions towards factors influencing practical work in chemistry of secondary schools?

- What do you think the possible physical resource that is influencing practical work in chemistry in secondary schools?

- To what extent do Information and Communication Technology (ICT) and computer based software application skills assist practical works in chemistry?

This paper is organized as follows: Section 2 gives an overview of practical work in science. Section 3 describes a methodology of study. Section 4 describes the finding of the study and section 5 presents discussion based on the finding and finally Section 6 concludes the paper. 


\section{Related Works}

Practical work has been defined as teacher demonstrations; class practices, with all learners on similar tasks, working in small groups; a circus of 'experiments' with small groups engaged in different activities, rotating in a carousel; investigations, organized in one of the above two ways; and problem-solving activities [4]. According to a framework of SCORE for practical science in schools [5], defining practical work in science as 'a "hands-on" learning experience which prompts thinking about the world in which we live'. The related report [6] has a list of activities that could be considered to be practical work. These fall into two main categories: Core activities: Investigations, laboratory procedures and techniques, and fieldwork. These 'handson' activities support the development of practical skills and help to shape students' understanding of scientific concepts and phenomena. Directly related activities: Teacher demonstrations, experiencing phenomena, designing, and planning investigations, analyzing results, and data analysis using ICT. These are closely related to the core activities and are either a key component of an investigation or provide valuable first-hand experiences for students. A range of activities was also identified which complement, but should not be a substitute for, practical work. These complementary activities include science-related visits, surveys, presentations and role play, simulations including a use of ICT, models and modeling, group discussion, and group text-based activities. They have an important role to play supporting practical work in developing the understanding of science concepts.

However, according to the literature, in many countries of the world and particularly in the developing countries, the effective implementation of the practical work is a general problem accompanied by several constraints. For instance, the absence of adequate conditions, equipment and laboratory materials, including financial resources to teach practical science; poor preparation of teachers; poor implementation of procedures; overwhelming number of activities demanded by the new curricula and lack of qualified teachers are some of the problems confronting the process of science teaching, particularly in African settings [7-9]. Furthermore, most of the experiments and laboratory activities are conducted using a 'recipe-style' in which the students are required only to follow a set of steps to demonstrate and verify the scientific concepts already known [9]. In relation to this, [10], states that if the goals and objectives are not expressed in terms of being able to apply scientific knowledge, understanding and skills there is a danger of students simply following 'recipes' during practical activities. This way of doing laboratory work or practical work has been criticized for its distortion of what science really is, encouragement of rote learning rather than meaningful inquiry-oriented learning and failure to provide students with opportunities to plan investigations and perform their own experiments, manipulate equipment and materials so that they can construct their own knowledge of phenomena and related scientific concepts $[9,11-13]$.

\section{Methodology of the Study}

The study adopts descriptive survey design. Descriptive research is a study designed to depict the participants in an accurate way and a method is appropriate which enables to make an assessment and investigation of the events [14]. Hence, the present study employed multi-method research (both quantitative and qualitative methods) to assess factors influencing practical work in chemistry in the secondary school in Wolaita Zone, Ethiopia.

\subsection{Population, Sample Size and Sampling Techniques}

The study was conducted on 50 government secondary schools in Wolaita Zone, Ethiopia. The targeted populations were chemistry teachers, students, and school principals of Wolaita zone. The sample size for the study was selected by using different techniques. All 56 chemistry teachers were purposively selected, to 
respond questionnaire, among the teachers who were selected for science laboratory training from secondary schools in Wolaita Zone, organized by the Wolaita Sodo University in semester break of 2015/2016 academic year. The researchers have gathered the data purposefully from this volunteer sample contains a high proportion of real enthusiasts and probably provide a positive view. To gather data from learners, five sample government secondary schools (Areka, Bodit, Gasuba, Gununo and Sodo) were selected and from each sample schools 15 respondent students were selected simple randomly to respond questionnaire. Five school principals were also randomly selected from the same 5 government secondary schools to conduct interviews.

\subsection{Data Collection Instrument}

In order to collect sufficient and rich data, variety of instruments such as structured questionnaires adapted from Adedayo and Julius [15], and semi-structured questionnaires for focus group discussion (FGD) were used to gather information from chemistry teachers; structured questionnaire in Amharic (official language of Ethiopia) were prepared for students based on the basic research questions and objectives of the study; and unstructured interviews were used to gather information from school principals.

\subsection{Data Analysis}

The data gathered using questionnaire were coded appropriately and analysed. For quantitative data, Statistical Package for Social Sciences (SPSS) version 20.0 was utilised. The main statistics yielded were analyzed simple quantitative descriptive such as frequency count and percentage. Percentage and frequency are important data analysis techniques to show the main constraints of influencing practical work in chemistry. Similarly, the data collected from FGD, open-ended questionnaires and interview were also coded and categorized into themes and analyzed in words to develop an important idea which can support and emphasize the numerical data.

\subsection{Ethical Consideration}

The study was conducted based on the consent of the participants explaining the objective of the study, which was purely for academic purpose only. Overall, all respondents were given all their responses voluntarily.

\section{Results}

Data solicited from the participants via questionnaire, FGD and interview are themed and analysed along the research questions as follows:

\subsection{Teachers' Perception towards Factors Influencing Practical Work in Chemistry}

In order to gather the views of the teachers towards factors that influencing practical work in chemistry the respondents were required to indicate their views. As shown in table 1, the majority of respondents $(87.50 \%)$ claimed that the lack of awareness and motivation of school managements to practical work is the major factor that influences practical work in chemistry. 53.57, 41.86, 39.29, 32.14 and $28.57 \%$ of the respondent claimed that the full-time occupancy of chemistry teacher, low commitment of teachers for the practical classes, absenteeism of teachers' from practical class, teachers poor knowledge about practical work and low qualification of chemistry teacher are influencing practical work in chemistry of secondary schools, respectively.

Moreover, the respondents replied through open-ended question and FGD that, "teachers' skill gap towards practical work" and "lack of competent staff" is the factors that influenced practical work in chemistry. The 
results showed that the Practical works in chemistry of secondary schools in Wolaita zone are being scared by the measurements involved, lack of motivation and awareness of school managements, the full-time occupancy of chemistry teachers, low commitment of teachers for the practical classes, absenteeism of teachers' from practical class, teachers poor knowledge about practical works, low qualification of chemistry teachers/ attendant, teachers skill gap towards practical work and lack of competent staff. This result is inconsistent with the report of related work by Adedayo [15].

Table 1. Frequency and Percentage Distribution of Teachers' Perception toward Factors Influencing Practical Work in the Chemistry of Secondary Schools.

\begin{tabular}{|c|c|c|c|c|}
\hline \multirow{2}{*}{$\begin{array}{l}\text { Responses } \\
\text { What are the possible factors influencing Practical work in } \\
\text { chemistry of secondary schools? }\end{array}$} & \multicolumn{2}{|c|}{ Yes } & \multicolumn{2}{|c|}{ No } \\
\hline & Frequency & $\%$ & Frequency & $\%$ \\
\hline Teachers' poor knowledge of practical work & 18 & 32.14 & 38 & 67.86 \\
\hline Low qualification of chemistry teachers & 16 & 28.57 & 40 & 71.43 \\
\hline The full-time occupancy of chemistry teachers & 30 & 53.57 & 26 & 46.43 \\
\hline Absenteeism of teachers from practical class & 22 & 39.29 & 35 & 62.50 \\
\hline low commitment of teachers for practical classes & 24 & 42.86 & 32 & 57.14 \\
\hline Lack of awareness and motivation of school management & 49 & 87.50 & 7 & 12.50 \\
\hline
\end{tabular}

\subsection{Teachers' Perception towards Physical Resources Influencing Practical Work in Chemistry of Secondary Schools}

Out of the total 56 respondent chemistry teachers, the majority $(83.93,80.36$ and $76.79 \%)$ replied that the possible laboratory-related factors influencing practical work in chemistry are lack of types of equipment in the laboratory, too short period allocated for the practical activities and lack of practical textbooks (manual) in the secondary schools respectively. Furthermore, 64.29, 60.71 and $44.64 \%$ of the respondents claimed that the lack of competent laboratory attendant, ineffective maintenance of laboratory instruments and lack of separate chemistry laboratory room are influencing the practical work in chemistry (table 2). On the other hand, $55.36 \%$ of respondents claimed that in their school being there of separate laboratory room for chemistry practical work. However, they were indicating that other factors influencing practical work in chemistry related to physical resources through open-ended question and FGD are: "unsafe laboratory rooms to conduct practical work, "lack of laboratory equipment, chemicals, and personal protective safety equipment" and lack of policy and regulation of waste management. Among the respondent replied, "Expired chemicals and contaminated equipment in the workplace of their laboratory unsafely stored for the long period of years, because of this chemistry teachers as well as students worry about themselves rather than conducting practical work in the laboratory room." Laboratory has been given a central and distinct role in science education to conduct practical activities in chemistry. However, the findings are indicating a lot of concern has been shown about the inadequacy of chemistry laboratory in Wolaita Zone, Ethiopia. 
Table 2. Frequency and Percentage Distribution the Possible Laboratory-Related Factors Influencing Practical Work in the Chemistry of Secondary Schools.

\begin{tabular}{|c|c|c|c|c|}
\hline Responses & \multicolumn{2}{|c|}{ Yes } & \multicolumn{2}{|c|}{ No } \\
\hline $\begin{array}{l}\text { factors influencing Practical work in chemistry of } \\
\text { secondary schools? }\end{array}$ & Frequency & $\%$ & Frequency & $\%$ \\
\hline Lack of separate chemistry laboratory & 25 & 44.64 & 31 & 55.36 \\
\hline Lack of equipment in the laboratory & 47 & 83.93 & 9 & 16.07 \\
\hline Lack of practical chemistry text book (manual) & 43 & 76.79 & 13 & 23.21 \\
\hline Lack of competent laboratory attendant & 36 & 64.29 & 20 & 35.71 \\
\hline Ineffective maintenance of laboratory & 22 & 60.71 & 34 & 39.29 \\
\hline Too short period for practical work & 45 & 80.36 & 11 & 19.64 \\
\hline
\end{tabular}

\subsection{Teachers' Perception towards Students Attitudes to Practical Work in Chemistry of Secondary Schools}

Chemistry teachers were requested to respond the extent of their students' attitude towards practical activities in chemistry. As shown in Fig 1, the majority of respondents (44.64 and $35.71 \%$ ) claimed that the attitude of students towards practical work is medium and low respectively. The respondents were also requested through open-ended question and FGD their students' low attitude towards practical work also replied that "Students' population is larger than the available apparatus during practical class"; "the working environment is unsafe to conduct practical activities" and "language difficulty to understand and interpret practical activities in their textbook".

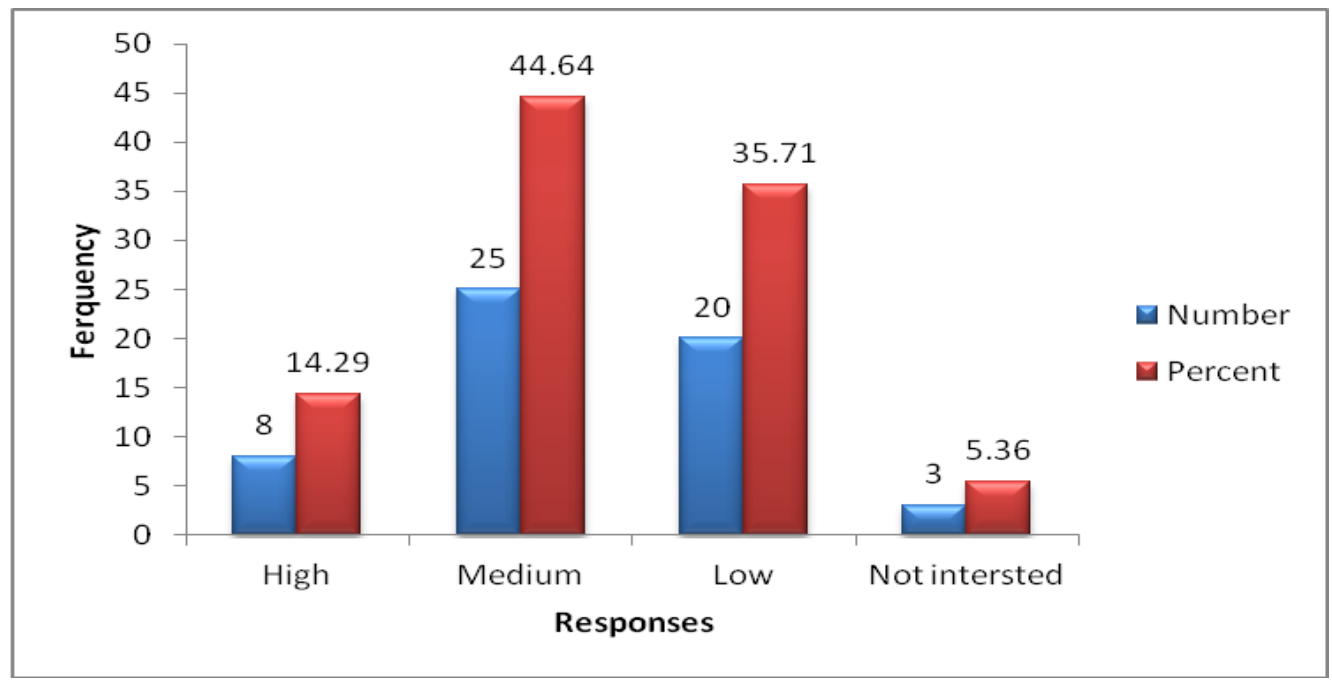

Fig.1. The Extent of Students' Motivation Towards Conducting Practical/ Laboratory Work.

\subsection{Information and Communication Technology (ICT) Skill to Assist Practical Work in Chemistry with Computer-Based Software Application}

The objective of using information technology to assisted instruction is using image, sound, animation and 
other means to stimulate the sensory of students and attract interests of students. Information technology is used in case teaching can change abstract problem into image of problems, and this can help students to master and understand the abstract content. But, using too much information technology certainly will affect the logical thinking ability of students to be provided. It may lighten the students to study the difficult points of concern, and affect the teaching of the actual effect [16].

In the present study, the teachers' knowledge and familiarity with basic computer skills and computer-based software application which to assist practical work in chemistry were assessed. The respondents were requested to describe their knowledge and familiarity of basic computer skills and software application, the majority of respondents $(58.5 \%)$ claimed that they have no basic computer skills. And also 98.21, 89.29, 82.14 \% of the respondents also replied that they are not familiar with software applications to assist with practical works in chemistry (Fig 2). Moreover, the respondents were requested why they are not familiar with those applications through open-ended question and during FGD, and the majority of teachers claimed that "lack of computer laboratory in their schools", "there is a lack of awareness and skill regarding the computer applications assist with practical works in chemistry".

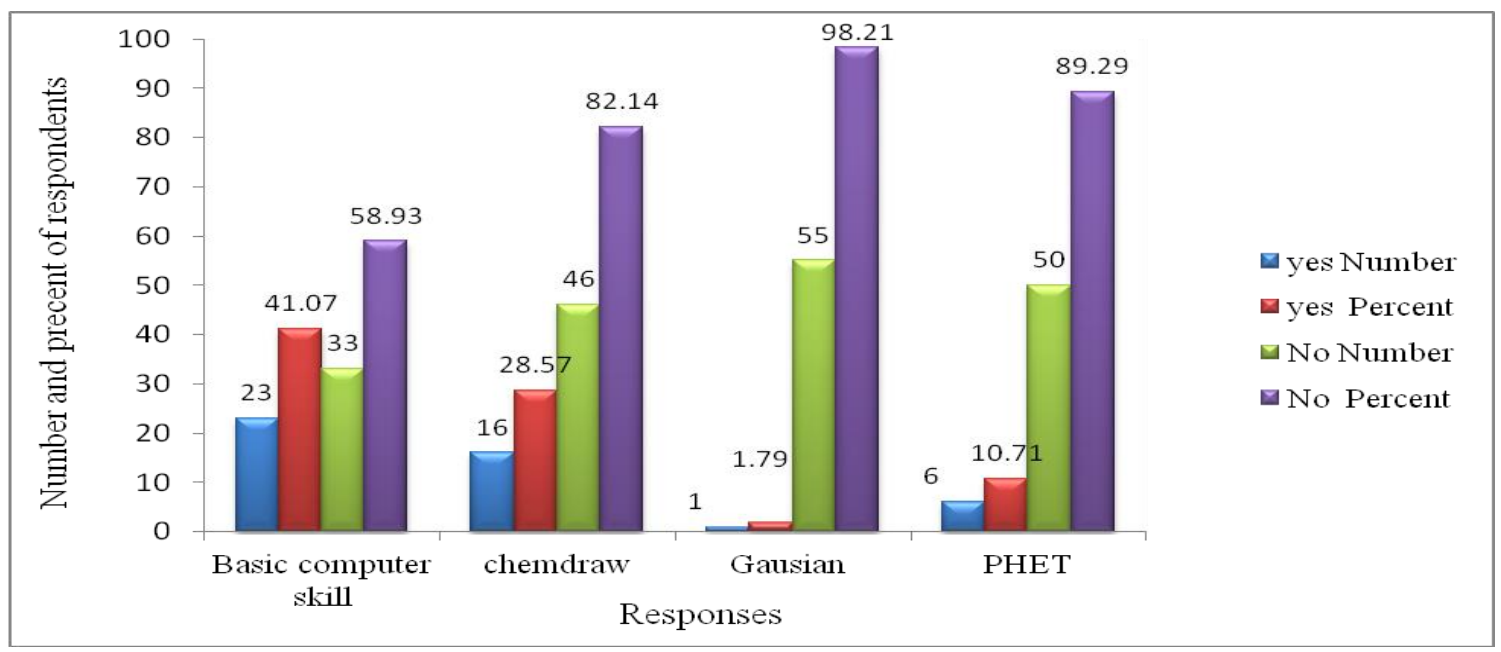

Fig.2. Familiarity with Basic Computer Skill and Computer Based Software Application to Support Practical Work in Chemistry.

\subsection{Learners' Perspectives to Factors Influencing Practical Work in Chemistry}

The learners' questionnaire utilized a four-point Likert scale in which the respondents were required to give their views: strongly agree (SA), agree (A), Disagree (D) or strongly disagree (SD). As shown table 3, the majority of respondents $(26.67 \%$ and $56.00 \%)$ expressed their view as strongly agree and agree to the statements, prior negative impressions about practical work in chemistry as being difficult. In addition to this the respondents showed their views for the statements, laboratory chemicals make them fear chemistry $(26.67 \%$ strongly agree and $34.67 \%$ agree), Students' population is larger than the available apparatus during chemistry practical class $(53.33 \%$ strongly agree and $40.00 \%$ strongly agree), unsafe laboratory rooms to conduct practical classes (6.67\% strongly agree and $53.33 \%$ strongly agree). They also agreed to the statements, such as school managements paying less attention toward practical work $(38.67 \%)$, chemistry teachers and laboratory attendant do not encourage them to practical work (40.00\%).

Moreover, the majority of respondents strongly disagreed and disagreed with the statements such as their intelligence level cannot cope with chemistry practical activities $(22.67 \%$ and $61.33 \%)$ and students do not have an interest in attending chemistry practical class (34.67\% and 53.33) respectively. Thus, the finding 
revealed that the students' interest towards practical work in chemistry is generally positive. However, the attitude of students towards practical work, influenced by prior negative impression about practical work in chemistry as being difficult; they have low familiarity of handling chemicals, students' population is larger than the available apparatus during chemistry practical class and unsafe laboratory environment to conduct practical classes influence their views regarding practical works in high school chemistry courses. The students' responses agree with their teachers' perceptions regarding low attitude toward practical work in chemistry due to their attitude influenced by the physical resources at large rather than their interest towards practical work.

Table 3. Frequency and Percentage Distribution of Learners' Perceptions towards Factors Influencing Practical Work in Chemistry

\begin{tabular}{|c|c|c|c|c|c|c|c|c|}
\hline \multirow{2}{*}{ Responses } & \multicolumn{2}{|c|}{ SA } & \multicolumn{2}{|c|}{$\mathrm{A}$} & \multicolumn{2}{|c|}{$\mathrm{D}$} & \multicolumn{2}{|c|}{ SD } \\
\hline & $\mathrm{N}$ & $\%$ & $\mathrm{~N}$ & $\%$ & $\mathrm{~N}$ & $\%$ & $\mathrm{~N}$ & $\%$ \\
\hline $\begin{array}{l}\text { Students' intelligence level cannot } \\
\text { cope with chemistry practical } \\
\text { activities }\end{array}$ & 0 & 0.00 & 12 & 16.00 & 46 & 61.33 & 17 & 22.67 \\
\hline $\begin{array}{l}\text { Students do not have interest in } \\
\text { attending chemistry practical class }\end{array}$ & 0 & 0.00 & 9 & 12.00 & 40 & 53.33 & 26 & 34.67 \\
\hline $\begin{array}{l}\text { prior negative impression about } \\
\text { practical chemistry as being } \\
\text { difficult }\end{array}$ & 20 & 26.67 & 42 & 56.00 & 10 & 13.33 & 3 & 4.00 \\
\hline $\begin{array}{l}\text { Laboratory chemicals make them } \\
\text { fear chemistry }\end{array}$ & 20 & 26.67 & 26 & 34.7 & 18 & 24.00 & 11 & 14.67 \\
\hline $\begin{array}{l}\text { Chemistry teachers and laboratory } \\
\text { attendant do not encourage } \\
\text { students toward practical work }\end{array}$ & 0 & 0.00 & 30 & 40.00 & 35 & 46.67 & 10 & 13.33 \\
\hline $\begin{array}{l}\text { School managements paying less } \\
\text { attention topractical work. }\end{array}$ & 0 & 0.00 & 29 & 38.7 & 40 & 53.33 & 6 & 8.00 \\
\hline $\begin{array}{l}\text { Students' population is larger than } \\
\text { the available apparatus during } \\
\text { chemistry practical class }\end{array}$ & 40 & 53.3 & 30 & 40.00 & 5 & 6.67 & 0 & 0.00 \\
\hline $\begin{array}{l}\text { Unsafe laboratory environment to } \\
\text { conduct practical classes }\end{array}$ & 5 & 6.67 & 40 & 53.33 & 30 & 40.00 & 0 & 0.00 \\
\hline
\end{tabular}

$\mathrm{N}=$ Frequency, strongly agree (SA), agree (A), Disagree (D) or strongly disagree (SD)

\subsection{School Principals’ Perceptions towards Factors Influencing Practical Work in Chemistry}

School principals were also requested through an unstructured interview questionnaire to respond the factors affect the practical work in chemistry. They claimed that: "Low grant to full fill all facilities in the laboratories, "unplanned distribution of the equipment", "lack of policy and regulation to waste management", lack of skilled laboratory attendant" and "low motivation of chemistry teachers regarding practical work" are the major influencing factors of practical work in chemistry.

\section{Discussion}

Practical work in science has several purposes, including practicing skills, developing specific knowledge and understanding of science, and developing an understanding of the processes of scientific inquiry. It has the potential to contribute to meaningful learning in science [17]. However, the finding of the present study was considered a number of factors that influence practical works in the chemistry of secondary schools in Wolaita zone, Ethiopia. Key factors among them were teachers' poor knowledge of practical work, full-time occupancy of chemistry teachers by the theoretical classes, absenteeism of the teacher at practical classes, late commencement of teaching practical class; lack of awareness and motivation from school managements and unsafe working environments, lack of separate chemistry laboratory, lack of equipment in the laboratory, too 
short period allocated for practical work and lack of knowledge and familiarity of chemistry teachers to modern technology. Our observation is inconsistent with the report by Science Community Representing Education [17], in the United Kingdom, which identified several factors that impacted on the implementation of practical work in schools. Their findings in the research include the lack of equipment funding, lack of understanding of the aims of the changes in the science curriculum, the shortage of time and lack of resources for practical work, the lack of mentorships for inexperienced teachers in order to build confidence in practical work and the inadequate opportunities for training and professional development. And also the present study was also agreed to with Motswiri report, observed that classroom practices in most secondary school Chemistry lessons are characterized by chalk-and-talk and little practical work [18]. Moreover, the finding of present study consistency with the reports of Soyibo and Ajayi, that most secondary schools have no science laboratories and the few that have them are ill-equipped and poorly maintained, respectively [19 and 20], and materials can also serve as a primary influence on how teachers should teach science practical [21].

Therefore, in order for practical work to be effective in producing meaningful teaching and learning of chemistry, the teachers should develop activities that engage the learners in scientific investigations which focus their minds on the activity and its outcome. Teaching chemistry in secondary schools should develop essential scientific skills in the learners by infusing them into a creative mind to enhance their technological applications; teachers, as well as school managements, need to develop a positive attitude towards practical work at the secondary school level. The role of modern technology in education is commonly associated with the process of educational innovation and in curricula and it enables extensive visualization recourses for chemistry educators [22]. Information and Communication Technology (ICT), has the potential to impact on practical science in a number of ways. These include sensors for ease of data collection, computational data analysis tools, computer simulations to present science concepts and the Internet for information, including data, concepts, and contexts for science. Visualization technologies include computer-based molecular modeling, animations, computer assisted conceptual framework modeling and microcomputer-based laboratories. However, the finding revealed that chemistry teachers in the secondary schools have with the low familiarity of basic computer and software application skill to support practical work in chemistry by computer-assisted teaching and learning methods. Therefore, the chemistry teachers need to develop their skills towards modern technology to assist their students.

\section{Conclusion}

It can be concluded that: teachers-related factors that influence practical work in chemistry are teachers' poor knowledge of practical work, full-time occupancy of chemistry teachers by the theoretical classes, absenteeism of the teacher at practical classes, late commencement of teaching practical class; lack of awareness and motivation from school managements and unsafe working environments in the schools. Laboratory-related factors are a lack of separate chemistry laboratory, lack of equipment in the laboratory and too short period allocated for practical work. And also law attitude of students towards practical works in chemistry. Moreover, teachers' low level of expectation to developments of ICT would improve practical work in science is influencing practical work in chemistry.

In order to improve practical work in chemistry, the following steps were recommended: in case where the students outnumbered the available apparatus for a typical experiment, the teacher should apply grouping method of instruction to enhancing the motivation of students toward the practical work; The teachers should attend to their chemistry practical classes regularly and punctually; The school managements should understand the value of the practical work in chemistry and be willing to provide the time, location, facilities and staff resources for its implementation and should make provision for a separate laboratory room for chemistry and stock it with needed apparatus. The school management does not generally participate directly in practical works, but they might visit debriefing meetings, motivate and recognized a teacher who is a model for the staffs in practical work. It is also recommended that the government and concern bodies take a measurement to 
establish safe and secure chemical laboratory in schools; Distribution of the equipment should be carefully planned and coordinated; The government on their part should recruit skilled chemistry teachers who could handle practical aspect of chemistry competently; Workshops and seminars should be organized for the teachers and school managements on practical work chemistry to create common understanding and awareness.

\section{Acknowledgment}

Authors would like to acknowledge Wolaita Sodo University for providing facility supports for this study and secondary school chemistry teachers, students and school principals of Wolaita zone for providing real information. Finally, Wolaita zone educational bureau for organizing training program for the respondents.

\section{References}

[1] Millar R. The role of practical work in the teaching and learning of science. National Academy of Sciences, Washington, DC, 2000.

[2] Science Community Representing Education, SCORE. Practical work in science: a report and proposal for a strategic framework, London, 2007.

[3] Ministry of Education, MoE. The education and training policy and its implementation. Addis Ababa: Ministry of Education, Ethiopia, 2010.

[4] Wellington J. (Ed.). Practical Work in School Science. Which Way Now? London: 1998. Routledge.

[5] Science Community Representing Education, SCORE. Getting practical: a framework for practical science in schools. London: DCSF, 2009a.

[6] Science Community Representing Education, SCORE. Practical work in science: a report and proposal for a strategic framework London: DCSF, 2009b.

[7] Motlhabane A. The Voice of the Voiceless: Reflections on Science Practical Work in Rural Disadvantaged Schools. Mediterranean Journal of social Sciences, 4(14): 165-173, 2013.

[8] Bekalo SA and Welford AG. Secondary pre-service teacher education in Ethiopia: its impact on teachers' competence and confidence to teach practical work in science. International Journal of Science Education, 21, 1293-1310, 1999.

[9] Hodson D. Practical work as a scientific method: The decades of confusion and distortion. Journal of Curriculum Studies, 28(2), 115-135, 1996.

[10] Woodley E. Practical work in school science. Why is it important? SSR, 91(335), 49-51, 2009.

[11] Hofstein A. and Maalmlok-Naaman R. The laboratory in science education: the state of the art. Chemistry Education Research and Practice, 8(2), 105-107, 2007.

[12] Domin DS. A review of laboratory instruction styles. Journal of Chemical Education, 76(4): 543-547, 1999.

[13] Shiland TW. Constructivism: The Implications for Practical work. Journal of Chemical Education, 76(1), 107-108, 1999.

[14] Wiersma W. Research method in education an introduction (6 edn), London sage publication, 1999.

[15] Adedayo and Julius O. Analysis of factors influencing students' attitudes towards the practical aspect of secondary school physics in Ekiti state. International Journal of Multidisciplinary Research and Development, 2(7), 417-421, 2015.

[16] Wei LI, Ruijin ZHOU, Peiqi DENG, Qiang FANG, Pengwei ZHANG. Construction of Case Teaching Model for Management Specialty Supported by Information Technology. I.J. Education and Management Engineering, 2(9), 44-48, 2012.

[17] Science Community Representing Education, SCORE. Practical Work in Science: A Report and 
Proposal for a Strategic Framework. Gatsby Technical Education Projects, 2008.

[18] Motswiri MJ. Supporting chemistry teachers in implementing formative assessment of investigative practical work in Botswana. Thesis. University of Twente, Enschede, 2004.

[19] Soyibo SK. A critical review of some of the causes of students' poor performance in science. Journal of Science Teachers Association of Nigeria, $27^{\text {th }}$ Annual Conference: 80-87, 1986.

[20] Ajayi PO and Julius O. Evaluation of the implementation of senior secondary school physics practical activities in Nigeria. Research in Curriculum Studies, 5(1), 90-99, 2008.

[21] Krajcik JS. McNeill KL and Reiser BJ. Learning-goals-driven design model: Developing curriculum materials that align with national standards and incorporate project-based pedagogy. Science Education, 92(1), 1-32, 2007.

[22] Kozma RB and Russell JW. 4M: Chem-multimedia and mental models in chemistry. Journal of Chemical Education, 71(8), 669-670, 1994.

\section{Authors' Profiles}

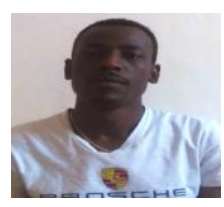

Mr. Mathewos Anza (MSc in organic chemistry) (born august 31, 1982) is lecturer in the department of chemistry, Wolaita Sodo University, Ethiopia. His research interest is isolation and characterization of natural products.

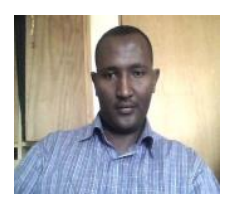

Mesfin Bibiso (PhD), (born June 30, 1980) is an Ethiopian young researcher in the Department of Chemistry, Wolaita Sodo University. Dr. Mesfin is Director of Institutional Quality Enhancement and Assurance of Wolaita Sodo University and member of Chemical Society of Ethiopia. His research interest focuses on exploring complex matrices such as food, water, soils and plants using advanced instruments.

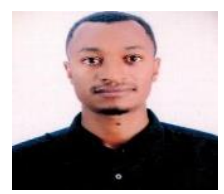

Mr. Abedelfeta Mohammad (MSc in Analytical chemistry) is lecturer in the department of chemistry, Wolaita Sodo University, Ethiopia. His research interest is water conservation and treatment technology.

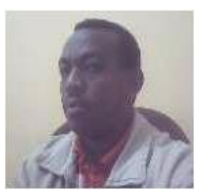

Berhanu Kuma has (PhD) in Agricultural Economics. Currently, he is Associate Professor of Agricultural of Economics and vice president for research and community services at Wolaita Sodo University in Ethiopia. Before joining Wolaita Sodo University two year ago, he worked at Ethiopian Institute of Agricultural Research for 13 years and became Senior Researcher.

How to cite this paper: Mathewos Anza, Mesfin Bibiso, Abedelfeta Mohammad, Berhanu Kuma,"Assessment of Factors Influencing Practical Work in Chemistry: A Case of Secondary Schools in Wolaita Zone, Ethiopia", International Journal of Education and Management Engineering(IJEME), Vol.6, No.6, pp.53-63, 2016.DOI: 10.5815/ijeme.2016.06.06 